\title{
GAMBARAN KADAR HIDRASI KULIT DAN KEJADIAN DERMATITIS KONTAK IRITAN PADA PETUGAS KEBERSIHAN DI UNIVERSITAS TARUMANAGARA
}

\section{Indi Chairunnisa $^{1}$, Linda Julianti Wijayadi ${ }^{2}$, Sari Mariyati Dewi Nataprawira ${ }^{3}$}

\author{
${ }^{1}$ Fakultas Kedokteran Universitas Tarumanagara, Jakarta, Indonesia \\ Email:chairunnisaindi@gmail.com \\ ${ }^{2}$ Departemen Ilmu Penyakit Kulit dan Kelamin Fakultas Kedokteran Universitas Tarumanagara, Jakarta, Indonesia \\ Email: lindaj@fk.untar.ac.id \\ ${ }^{3}$ Departemen Histologi Fakultas Kedokteran Universitas Tarumanagara, Jakarta, Indonesia
}

\begin{abstract}
Irritant contact dermatitis (DKI) is a non-immunologic skin inflammation reaction caused by contact with irritants. Janitor is a worker who does a lot of wet work that will repeatedly contact with irritants such as acids, bases, detergents, soap, water, solvents, etc., so that there will be damage to the skin barrier function that starts with loss of the lipid layer and Natural Moisturizing Factor (NMF) so it will reduce skin hydration levels and increase TransEpidermal Water Loss (TEWL). This makes the skin condition becomes dry and the skin defense decreases so that it is easier for DKI. The purpose of this study was to determine the description of skin hydration levels and the incidence of irritant contact dermatitis in janitors at Tarumanagara University. This research is descriptive with cross sectional design. A total of 60 people from the janitor became the subject of research. The level of skin hydration is measured by a corneometer. The incidence of DKI in the cleaning staff at Tarumanagara University was 10\%, the level of skin hydration in the janitor at Tarumanagara University found hydration levels of dry skin on the right palm (76.7\%), left palm (76.7\%), back of the hand right (56.7\%), and back of the left hand (56.7\%). In subjects who experience DKI, levels of hydration of very dry skin on the palm (left-right) and hydration of dry skin on the back of the hand (left-right), and the factors that influence the occurrence of DKI are: gender (female), frequency of washing hands with soap per day, frequency and duration of contact with toilet and floor cleaning products per day and the use of personal protective equipment (PPE), and so it is recommended that cleaners always use PPE when working to prevent DKI and use moisturizers on dry skin.
\end{abstract}

Keywords: skin hydration level; irritant contact dermatitis; korneometer; janitor.

\begin{abstract}
ABSTRAK
Dermatisis kontak iritan (DKI) adalah suatu reaksi peradangan kulit non-imunologik yang disebabkan oleh kontak dengan bahan iritan. Petugas kebersihan merupakan pekerja yang banyak melakukan pekerjaan basah yang akan kontak berulang dengan bahan iritan seperti asam, basa, detergen, sabun, air, pelarut, dll, sehingga akan terjadi kerusakan fungsi sawar kulit yang dimulai dengan kehilangan lapisan lipid dan Natural Moisturizing Factor (NMF) sehingga akan menurunkan kadar hidrasi kulit dan meningkatkan TransEpidermal Water Loss (TEWL). Hal tersebut membuat kondisi kulit menjadi kering dan pertahanan kulit menurun sehingga lebih mudah terjadi DKI. Tujuan penelitian ini untuk mengetahui gambaran kadar hidrasi kulit dan kejadian dermatitis kontak iritan pada petugas kebersihan di Universitas Tarumanagara. Penelitian ini bersifat deskriptif dengan desain cross sectional. Sejumlah 60 orang dari petugas kebersihan menjadi subjek penelitian. Kadar hidrasi kulit diukur dengan alat korneometer. Angka kejadian DKI pada petugas kebesihan di Universitas Tarumanagara sebesar $10 \%$, Kadar hidrasi kulit pada petugas kebersihan di Universitas Tarumanagara didapatkan kadar hidrasi kulit kering pada telapak tangan kanan (76,7\%), telapak tangan kiri (76,7\%), punggung tangan kanan (56,7\%), dan punggung tangan kiri (56,7\%). Pada subjek yang mengalami DKI didapatkan kadar hidrasi kulit sangat kering pada telapak tangan(kiri-kanan) dan hidrasi kulit kering pada punggung tangan (kiri-kanan), dan faktor-faktor yang mempengaruhi kejadian DKI adalah: jenis kelamin (perempuan), frekuensi cuci tangan dengan sabun per hari, frekuensi dan lama kontak dengan produk pembersih toilet maupun lantai per hari dan penggunaan alat pelindung diri (APD), dan sehingga disarankan agar petugas kebersihan selalu memakai APD dengan lengkap saat bekerja untuk mencegah DKI dan menggunakan pelembab pada kulit yang kering.
\end{abstract}

Kata Kunci : kadar hidrasi kulit, dermatitis kontak iritan, korneometer, petugas kebersihan. 


\section{PENDAHULUAN}

Petugas kebersihan merupakan pekerjaan basah yang sering kontak dengan bahan iritan yaitu produk pembersih toilet dan lantai yang mengandung zat yang bersifat iritan. Hal ini akan meningkatkan terjadinya dermatitis kontak iritan kepada orang yang bekerja sebagai petugas kebersihan.(Behroozy \& Keegel, 2014; Frosch \& Kügler, 2011),

Dermatitis kontak iritan (DKI) merupakan reaksi peradangan kulit non- imunologik. Pada DKI kerusakan kulit terjadi langsung tanpa didahului proses pengenalan atau sensitisasi yang disebabkan karena kontak dengan bahan yang bersifat iritan. Berdasarkan jenis bahan iritan DKI dibagi menjadi dua, DKI akut yang terjadi akibat kontak dengan bahan iritan kuat dan DKI kronis kumulatif yang diakibatkan kontak berulang dengan bahan iritan lemah. Dermatitis kontak iritan ditandai dengan munculnya gejala eritema, bula, skuama, edema, kulit kering.(Armado et a1., 2008; Menaldi et a1., 2016)

Pada sebuah studi epidemiologi di Indonesia 97\% dari 389 kasus dermatitis kontak akibat kerja (DKAK), 66,3\% merupakan dermatitis kontak iritan. (Hudoyono, 2002) Penelitian yang dilakukan oleh Saftarina dkk terhadap petugas cleaning service di Rumah Sakit Umum Abdoel Moeloek didapatkan 47 dari total 102 petugas mengalami dermatitis kontak akibat kerja.(Saftarina et a1., 2015). Dermatitis kontak iritan terjadi karena kerusakan fungsi sawar kulit yang diperankan oleh stratum korneum akibat kontak berulang dengan bahan iritan. Stratum korneum merupakan lapisan terluar epidermis yang berfungsi mempertahankan kadar air di kulit. Kerusakan pada stratum korneum akibat paparan bahan iritan dimulai dengan kehilangan lapisan lipid dan Natural Moisturizing Factor (NMF) sehingga akan menurunkan kadar hidrasi kulit dan meningkatkan TransEpidermal Water Loss (TEWL). Hal tersebut mengakibatkan menurunnya fungsi dari sawar kulit yang menyebabkan kondisi kulit menjadi kering dan pertahanan kulit menurun. (Seidebari, 2000; Siddappa, 2003).

Universitas Tarumanagara merupakan salah satu perusahaan yang mempekerjakan petugas kebersihan dalam jumlah yang cukup banyak dan berisiko mengalami DKI. Selain itu belum didapatkannya juga data mengenai kejadian DKI pada petugas kebersihan di Universitas Tarumanagara. Berdasarkan kedua hal tersebut penelitian ini bertujuan untuk mengetahui gambaran kadar hidrasi kulit dan kejadian dermatitis kontak iritan pada petugas kebersihan di Universitas Tarumanagara.

\section{METODE PENELITIAN}

Subjek penelitian ini berjumlah 60 orang petugas kebersihan di Universitas Tarumanagara. Metode penelitian yang digunakan adalah deskriptif dengan desain potong lintang (cross sectional). Pengumpulan data dilakukan dengan cara wawancara menggunakan kuisioner, pemeriksaan kadar hidrasi kulit menggunakan korneometer HL-611 pada daerah kulit yaitu telapak tangan kiri kanan, dan punggung tangan kiri - kanan. Hasil pengukuran hidrasi kulit dikelompokkan menjadi 5 kategori yaitu kadar hidrasi kulit $\leq 33 \%$ dikelompokkan sangat kering, 34-37\% kering, 38-42\% normal, $43-46 \%$ lembab, dan $\geq 47 \%$ sangat lembab, dan pemeriksaan fisik kelainan DKI dan diagnosis oleh dokter SpKK.

\section{HASIL PENELITIAN}

Selama periode penelitian didapatkan sebanyak 60 orang petugas kebersihan di Universitas Tarumanagara yang dapat dimasukkan sebagai subjek penelitian. Subjek penelitian memiliki karakteristik rerata usia 25 tahun yakni usia termuda 17 tahun dan tertua 45 tahun. Pada petugas kebersihan didapatkan laki-laki sebanyak 58,3\% dan perempuan 41,7\%. Didapatkan 10\% mengalami DKI. Berdasarkan usia kejadian DKI terbanyak pada kelompok usia 23 - 28 tahun $(50 \%)$, dengan jenis kelamin terbanyak perempuan $(66,7 \%)$. Subjek dengan DKI didapatkan 
terbanyak mencuci tangan dengan sabun $>6$ kali per hari $(100 \%)$. Berdasarkan penggunaan produk pembersih toilet maupun lantai lama kontak terbanyak $6-8$ jam per hari $(83,3 \%)$. Pada petugas dengan DKI penggunaan APD mayoritas tidak menggunakan APD saat bekerja (100\%). (Tabel1)

Tabel 1. Karakteristik Subjek Penelitian

\begin{tabular}{|c|c|c|}
\hline Karateristik Subjek Penelitian & \multicolumn{2}{|c|}{$\begin{array}{l}\text { Hasil } \\
\text { n ; \% }\end{array}$} \\
\hline Rerata usia & \multicolumn{2}{|c|}{$25(17-45)$} \\
\hline \multicolumn{3}{|l|}{ Jenis kelamin } \\
\hline Laki - laki & \multicolumn{2}{|c|}{$35(58,3 \%)$} \\
\hline Perempuan & \multicolumn{2}{|c|}{$25(41,7 \%)$} \\
\hline \multicolumn{3}{|l|}{ Kejadian Dermatitis Kontak Iritan } \\
\hline Ada & \multicolumn{2}{|c|}{$6 ; 10 \%$} \\
\hline Tidak ada & \multicolumn{2}{|c|}{$54 ; 90 \%$} \\
\hline Usia & Ada DKI & Tidak ada DKI \\
\hline 17-22 tahun & $2 ; 33,3 \%$ & $17 ; 31,5 \%$ \\
\hline 23-28 tahun & $3 ; 50 \%$ & $16 ; 29,6 \%$ \\
\hline 29-34 tahun & $1 ; 16,7 \%$ & $9 ; 16,7 \%$ \\
\hline $35-40$ tahun & $0 ; 0 \%$ & $7 ; 13 \%$ \\
\hline$>40$ tahun & $0 ; 0 \%$ & $5 ; 9,3 \%$ \\
\hline \multicolumn{3}{|l|}{ Jenis Kelamin } \\
\hline Laki-laki & $2 ; 33,3 \%$ & $33 ; 65 \%$ \\
\hline Perempuan & $4 ; 66,7 \%$ & $21 ; 35 \%$ \\
\hline \multicolumn{3}{|l|}{ Cuci tangan dengan sabun (x/hari) } \\
\hline $1-3$ & $0 ; 0 \%$ & $1 ; 1,9 \%$ \\
\hline $4-6$ & $0 ; 0 \%$ & $4 ; 7,4 \%$ \\
\hline$>6$ & $6 ; 100 \%$ & $49 ; 90,7 \%$ \\
\hline \multicolumn{3}{|c|}{$\begin{array}{l}\text { Lama kontak dengan produk pembersih lantai } \\
\text { maupun toilet (jam/hari) }\end{array}$} \\
\hline 1-3 jam/hari & $0 ; 0 \%$ & $15 ; 27,8 \%$ \\
\hline 4-5 jam/hari & $1 ; 16,7 \%$ & $15 ; 27,8 \%$ \\
\hline 6-8 jam/hari & $5 ; 83,3 \%$ & $24 ; 44,5 \%$ \\
\hline \multicolumn{3}{|l|}{ Penggunaan Alat Pelindung Diri } \\
\hline $\mathrm{Ya}$ & $0 ; 0 \%$ & $31 ; 51,7 \%$ \\
\hline Tidak & $6 ; 100 \%$ & $23 ; 48,3 \%$ \\
\hline
\end{tabular}

Pada pengukuran kadar hidrasi kulit berdasarkan lokasi didapatkan hasil kulit kering terbanyak pada telapak tangan kiri $76,7 \%$, telapak tangan kanan $76,7 \%$, punggung tangan kiri $56,7 \%$, dan punggung tangan kanan 56,7\%.(Tabel 2). 
Tabel 2. Hasil Pengukuran Kadar Hidrasi Berdasarkan Lokasi Pengukuran

\begin{tabular}{ccccccccc}
\hline & \multicolumn{7}{c}{ Lokasi pengukuran } \\
\cline { 2 - 8 } Hidrasi kulit & $\begin{array}{c}\text { Telapak } \\
\text { tangan kiri }\end{array}$ & $\begin{array}{c}\text { Telapak } \\
\text { tangan kanan }\end{array}$ & $\begin{array}{c}\text { Punggung } \\
\text { tangan kiri }\end{array}$ & $\begin{array}{c}\text { Punggung } \\
\text { tangan kanan }\end{array}$ \\
\cline { 2 - 9 } & $\mathrm{N}$ & $\%$ & $\mathrm{~N}$ & $\%$ & $\mathrm{~N}$ & $\%$ & $\mathrm{~N}$ & $\%$ \\
\hline Sangat kering & 6 & 10,0 & 3 & 5,0 & 7 & 11,7 & 6 & 10,0 \\
Kering & 46 & 76,7 & 46 & 76,7 & 34 & 56,7 & 34 & 56,7 \\
Normal & 4 & 6,7 & 3 & 5,0 & 9 & 15,0 & 13 & 21,7 \\
Lembab & 4 & 6,7 & 3 & 5,0 & 6 & 10,0 & 2 & 3,3 \\
\hline Total & 60 & 100 & 60 & 100 & 60 & 100 & 60 & 100 \\
\hline
\end{tabular}

Berdasarkan hasil pengukuran kadar hidrasi kulit pada telapak tangan kiri petugas kebersihan dengan DKI terbanyak didapatkan golongan kulit sangat kering $(6,67 \%)$, pada telapak tangan kiri yang tidak DKI terbanyak adalah golongan kulit kering (70\%).

Hasil pengukuran kadar hidrasi kulit pada telapak tangan kanan dengan DKI terbanyak didapatkan tergolong kulit sangat kering $(8,33 \%)$, pada telapak tangan kanan yang tidak DKI terbanyak adalah golongan kulit kering $(70 \%)$.

Hasil pengukuran kadar hidrasi kulit menunjukkan pada punggung tangan kiri pada subjek penelitian dengan DKI terbanyak kulit kering $(6,67 \%)$, pada punngung tangan kiri yang tidak DKI terbanyak kulit kering (50\%).

Hasil pengukuran kadar hidrasi kulit menunjukkan pada punggung tangan kanan dengan DKI terbanyak kulit kering (5\%), pada punngung tangan kanan yang tidak DKI terbanyak kulit kering $(53,3 \%)$. (Gambar 1).

\section{PEMBAHASAN}

Penelitian ini dilakukan terhadap 60 subjek (petugas kebersihan yang bekerja di Universitas Tarumanagara) dengan rerata usia adalah 25 tahun, dan sebanyak 58,3\% berjenis kelamin lakilaki. Pada penelitian ini didapatkan kejadian DKI pada subjek sebanyak 10\% dengan lokasi mayoritas di telapak tangan. Hal ini sejalan dengan penelitian Elston dkk, Paendong dkk, dan Septiani menunjukkan bahwa petugas kebersihan beresiko mengalami dermatitis kontak akibat kerja yaitu DKI, Kondisi ini dikarenakan petugas kebersihan terutama tangannya sering terpapar sabun, deterjen, dan pembersih lantai maupun kaca yang mengandung zat iritan. (Elston el al., 2001; Paendong et al., 2017; Septiani, 2012). Kontak berulang dengan bahan iritan menyebabkan pengikisan lipid pada stratum korneum sehingga terjadi peningkatan transepidermal water loss. (Chew \& Maibach, 2006; Eberting et al., 2014). Selain itu kerusakan pada stratum korneum ini menyebabkan mudahnya zat iritan masuk ke dalam epidermis yang menginduksi pelepasan sitokin proinflamasi seperti interleukin- $1 \alpha$, interleukin- $1 \beta$, interleukin- 6 dan tumor necrosis factor- $\alpha$ oleh 
keratinosit. Kondisi inilah yang kemudian disebut DKI. (Armado et a1., 2008)

Subjek yang mengalami dermatitis kontak iritan ini terbanyak pada kelompok usia 23 sampai 28 tahun. Sesuai dengan penelitian Erliana dan Lestari, yang menyatakan bahwa kejadian DKI mayoritas terjadi pada usia <30 tahun. Kejadian DKI tidak dipengaruhi oleh usia, namun dominasi usia kerja berada pada kelompok kurang dari 30 tahun sehingga kejadian DKI didominasi pada kelompok usia tersebut.(Erliana, 2009; Lestari \& Utomo, 2007). Pada kelompok usia tersebut, memiliki pengalaman kerja yang lebih sedikit dibandingkan dengan pekerja yang lebih tua. Sehingga kontak dengan bahan kimia masih sering terjadi pada pekerja muda. Pada pekerja yang lebih tua biasanya sudah berpengalaman dalam menangani bahan kimia, sehingga kontak bahan kimia dengan kulit semakin lebih sedikit. Selain itu juga berkaitan dengan tingkat pendidikan rendah, dimana akan kurang memperhatikan kebersihan diri dan kesadaran penggunaan APD. Pada penelitian ini tidak didapatkan data tingkat pendidikan subjek sehingga tidak dapat diketahui hubungannya dengan pendidikan. (Cohen, 1999; Paendong et al., 2017).

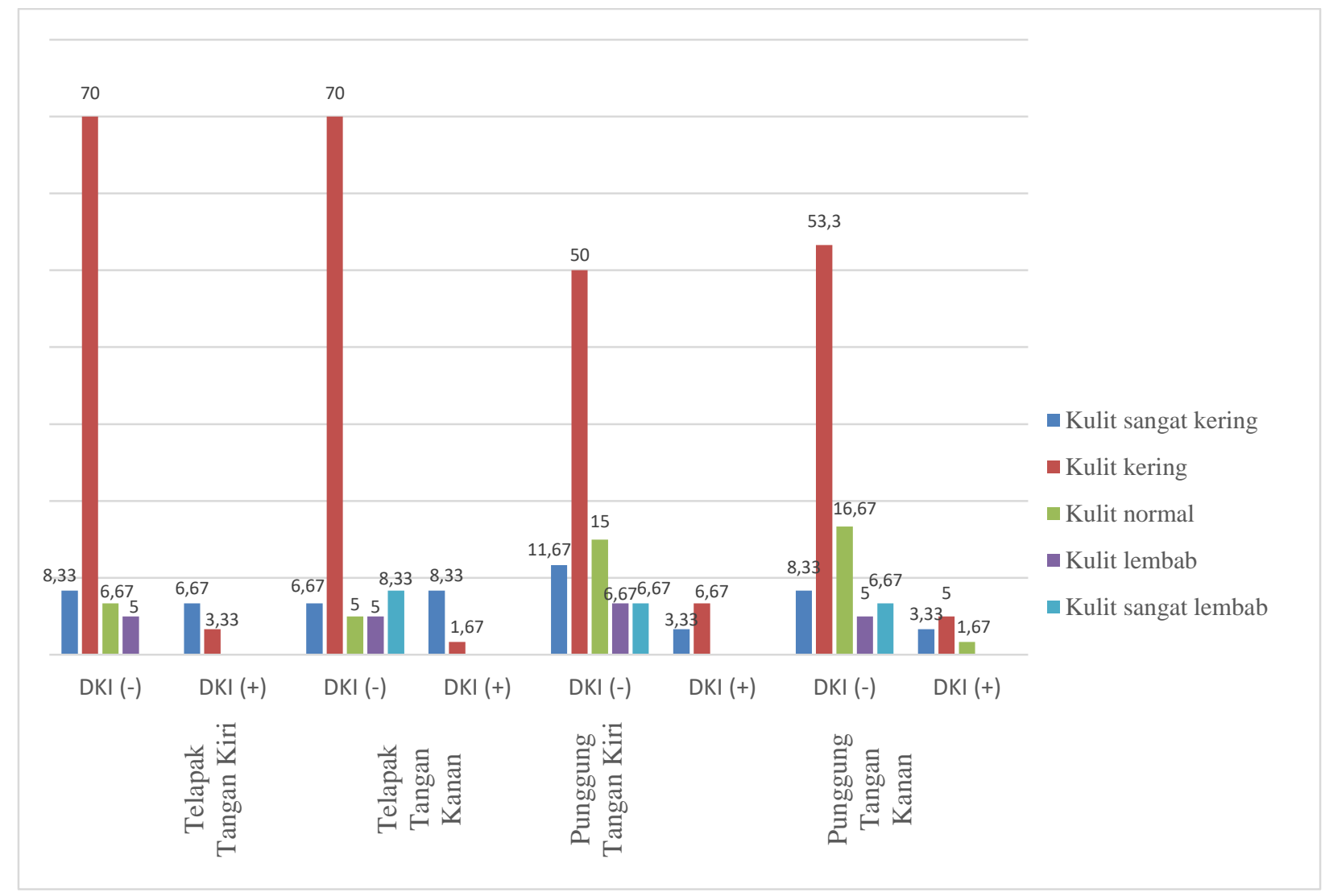

Gambar 1. Hasil Kadar Hidrasi Kulit Berdasarkan Kejadian Dermatitis Kontak Iritan Pada Telapak dan Punggung Tangan 
Berdasarkan jenis kelamin, Dermatitis kontak iritan ditemukan lebih banyak pada subjek perempuan yaitu sebesar $66 \%$. Hal ini sejalan dengan penelitian Nuraga, yang menyatakan perempuan lebih berisiko mendapat penyakit kulit akibat kerja salah satunya DKI dibandingkan dengan laki-laki. Hal ini karena terdapat perbedaan antara kulit pria dengan wanita, perbedaan tersebut dilihat dari jumlah folikel rambut, kelenjar sebasea dan hormon. Hormon testosteron pada laki-laki dapat menyebabkan stratum korneum laki-laki lebih tebal dibandingkan perempuan. Ketebalan kulit memengaruhi ketahanan kulit terhadap paparan bahan kimia. Selain itu, laki-laki mempunyai kelenjar sebasea yang lebih aktif daripada perempuan dan produksi sebum dua kali lebih banyak dari perempuan, sehingga pada perempuan kulit akan lebih kering dan rentan terjadi DKI dibandingkan laki-laki.(Nuraga et al., 2008; Honari et al., 2012).

Pada petugas kebersihan dengan DKI mayoritas melakukan cuci tangan dengan sabun $>6$ kali per hari $(100 \%)$. Cuci tangan yang berlebihan akan mengakibatkan terlalu sering atau lamanya kulit kontak dengan air dan sabun. Hal ini sesuai dengan penelitian Malik, yang menyatakan makin lama terpapar dengan air dapat mengakibatkan kerusakan lapisan stratum korneum sehingga rentan timbul kejadian dermatitis kontak. Hal ini mungkin disebabkan oleh karena air merupakan salah satu bahan iritan lemah yang bisa menembus lapisan stratum korneum dengan mudah dan dapat mengerosi kulit.(Malik, 2017; Cahill et al., 2012). Jenis sabun yang digunakan juga dapat merusak integritas kulit sehingga dapat mempengaruhi kelembapan kulit. Sabun yang bersifat basa akan menurunkan lemak pada kulit, meningkatkan TEWL dan menurunkan kadar hidrasi kulit sehingga rentan mengalami DKI.(Voegeli, 2008; Blaak et al., 2011).

Petugas kebersihan yang mengalami DKI memiliki lama kontak dengan cairan pembersih mayoritas selama 6-8 jam perhari. Penelitian ini sesuai dengan penelitian Nuraga, yang mendapatkan resiko dermatitis kontak lebih tinggi terjadi pada pekerja dengan lama kontak lebih dari sama dengan 8 jam per hari. (Nuraga et al., 2008). Semakin lama kontak dengan bahan iritan maka peningkatan TEWL semakin tinggi sehingga resiko terjadinya DKI pun meningkat.(Lurati, 2015).

Seluruh Petugas kebersihan dengan DKI tidak menggunakan APD saat bekerja. Hal ini sejalan dengan penelitian Erliana, yang menunjukan pekerja yang tidak menggunakan APD sangat beresiko mengalami DKI. (Erliana, 2009). Pemakaian APD secara baik dapat menghindari pekerja untuk kontak langsung dengan bahan iritan pada produk pembersih sehingga menurunkan resiko terkena kejadian DKI.(Cahyawati et al., 2011).

Hasil pengukuran kadar hidrasi kulit berdasarkan lokasi kulit didapatkan kadar hidrasi kulit kering pada 4 lokasi, yaitu pada kedua telapak tangan dan punggung tangan (kanan-kiri). Hal ini menyatakan bahwa tangan baik telapak dan punggung sering terpapar dengan sabun dan cairan pembersih. Hasil pengukuran ini sesuai dengan penelitian Scwindt dkk, yang menyatakan pemaparan berulang dengan detergen akan membuat kerusakan pada stratum korneum yang merusak integritas kulit sehingga TEWL meningkat dan hidrasi kulit menurun.( Voegeli, 2008; Schwindt et al., 1998).

Berdasarkan kejadian dermatitis kontak iritan didapatkan terbanyak kadar hidrasi kulit sangat kering pada telapak tangan kanan $(8,33)$. Hasil ini menunjukan bahwa telapak tangan kanan lebih sering terpapar bahan iritan dibanding tangan kiri. Hal ini menunjukan makin sering terpapar dengan bahan iritan menyababkan semakin rendahnya kadar hidrasi kulit sehingga resiko terkena DKI makin tinggi. (Lurati, 2015). Penurunan kadar hidrasi dapat dianjurkan untuk menggunakan pelembab untuk membuat kulit lembab dengan mengurangi TEWL sehingga menaikkan kadar 
hidrasi dalam kulit. pelembab memiliki kandungan, termasuk bahan oklusif dan humektan untuk merehidrasi dan menjaga kelembapan kulit, (Hurlow \& Bliss, 2011; Hannon et al, 2005) ada juga Olive oil yang memiliki komponen yaitu essential fatty acids (EFAs) yang berfungsi juga sebagai pertahanan barier kulit,membuat hidrasi kulit tetap terjaga dengan baik, dan mencegah terjadinya dermatitis. (Viola, 2009).

\section{KESIMPULAN DAN SARAN}

Hasil penelitian ini angka kejadian DKI pada pada petugas kebesihan di Universitas Tarumanagara adalah sebesar $10 \%$ subjek. Kadar hidrasi kulit berdasarkan lokasi kulit pada petugas kebersihan di Universitas Tarumanagara didapatlkan kadar hidrasi kulit kering pada telapak tangan kanan $(76,7 \%)$, telapak tangan kiri $(76,7 \%)$, punggung tangan kanan $(56,7 \%)$, dan punggung tangan kiri $(56,7 \%)$. Petugas kebersihan yang mengalami DKI memiliki kadar hidrasi kulit sangat kering pada telapak tangan dan kulit kering pada punggung tangan. Faktor-faktor yang mempengaruhi kejadian DKI adalah: jenis kelamin (perempuan), frekuensi cuci tangan dengan sabun per hari, lama kontak dengan produk pembersih toilet maupun lantai per hari dan penggunaan APD. Disarankan bagi petugas agar memakai APD yang sesuai saat bekerja untuk mencegah kontak langsung dengan bahan iritan dan penggunaan pelembab untuk mencegah penurunan kadar hidrasi kulit.

\section{Ucapan Terima Kasih}

Terima kasih disampaikan kepada LPPM UNTAR yang telah memberikan dukungan dana pada kegiatan penelitian ini. Terima kasih.

\section{REFERENSI}

Armado A, Taylor JS, Sood A. (2008). Irritant contact dermatitis. in: Freedberg IM, Eisen AZ, Wolff K, Austen KF, Goldsmith LA, Katz SI. Fitzpatrick's dermatology in general medicine. 7th Ed. USA: McGraw Hill, 395-401.

Behroozy, A., \& Keegel, T. G. (2014). Wet-work Exposure: A Main Risk Factor for Occupational Hand Dermatitis. Safety and Health at Work, 5(4), 175-180.

Blaak J, Wohlfart R, Schurer NY. Treatment of Aged Skin with a $\mathrm{pH} 4$ Skin Care Product Normalizes Increased Skin Surface $\mathrm{pH}$ and Improves Barrier Function: Results of a Pilot Study. JCDSA. 2011; 1: 50-8

Chew, A.L., Maibach, H.I. (2006). Ten Genotypes of Irritant Contact Dermatitis. Dalam: New York. Springer, 5-9.

Cohen DE. (1999). Occupational Dermatoses In: DiBerardinis LJ, editors. Handbook of Occupational Safety and Health, 2nd edition. Canada: John Wiley \& Sons Inc, 697-737.

Cahill J, Williams JDL, Matheson MC, Palmer AM, Burgess JA, Dharmage SC, et al. (2012). Occupational contact dermatitis: a review of 18 years of data from occupational dermatology clinic in Australia. Australia: Safe Work Australia.

Cahyawati, Imma Nur dan Irwan Budiono. (2011). Faktor yang Berhubungan dengan Kejadian Dermatitis Pada Nelayan. Jurnal Kesehatan Masyarakat, 6(2), 134-141

Elston DM, Ahmed DDF, Watsky KL, Schwarzenberger K. Hand dermatitis. August 2002. [cited 2017 Nov 17]. Available from: https://www.jaad.org/article/S0190-9622(02)000610/fulltext

Eberting, C.L., Blickenstaff, N., Goldenberg, A. (2014). Pathophysiologic treatment approach to irritant contact dermatitis. Curr Treat Options Allergy, 1(4), 317-28. 
Erliana.(2009). Hubungan karakteristik individu dan penggunaan alat pelindung diri dengan kejadin dermatitis kontak pada pekerja paving block CV. F. Lhoksumawe Tahun 2008, 8893

Frosch, P.J. \& Kügler, K.. (2011). Occupational Contact Dermatitis, 5th edition, Springer Verlag Berlin Heidelberg, 831-838.

Hudyono. (2002). Dermatosis akibat kerja. Majalah Kedokteran Indonesia. 49(9); 16-23.

Hurlow J, Bliss DZ. (2011). Dry skin in older adults. Geriatric Nursing. 32(4), 257-62.

Hannon, W.C. and Maibach, H.I. (2005). Eficacy of Moisturizers Assessed Through Bioengineering Techniques. In : Baran, R., Maibach, H.I., Taylor and Francis, editors. Textbook of Cosmetic Dermatology. Third Ed. Boca Raton USA: Tailor and Francis. 573592.

Honari G, Taylor JS, Sood A. (2012). Occupational skin diseases due to irritants and allergens. In: Goldsmith LA, Katz SI, Gilchrest BA, Paller AS, Leffell DJ, Wolff K, editors. Fitzpatrick's Dermatology in General Medicine (7th ed). New York: McGraw-Hill,; p. 2612-18

Lestari F, Utomo H.S. (2007). Faktor-faktor yang berhubungan dengan dermatitis kontak pada pekerja PT. Inti Pantja Press Industri Makara Kesehatan.11(2); 61-8

Lurati, A. (2015). 'Occupational risk assessment and irritant contact dermatitis. Workplace health and safety, 63 (2), 81-87.

Malik A.F. (2017). Hubungan Faktor Risiko Dermatitis Kontak Terhadap Kejadian Dermatitis Kontak Akibat Kerja Pada Para Pekerja Salon di Kelurahan Padang Bulan Tahun 2017. Fakultas kedokteran Universitas Sumatera Utara Medan.

Menaldi, S.W.S.L, Bramono K, Indriatmi W.( 2016). Ilmu Penyakit Kulit dan Kelamin. Edisi ke 7. Jakarta: Badan Penerbit FKUI, 157-160.

Nuraga W, Lestari F, Kurniwidjaja LM. (2008). Dermatitis kontak pada pekerja yang terpajan dengan bahan kimia di perusahan industri otomotif kawasan industri Cibitung Jawa Barat. Makara Kesehatan. 12 (2) : 68-9 